\title{
ULTIMATE STRENGTH AND ITS PRACTICAL EVALUATION OF CYLINDRICAL STEEL SHELL PANELS UNDER VARIOUS COMPRESSIONS
}

\author{
Tetsuya YABUKI*, Yasunori ARIZUMI** \\ and Shigeru YASHIRO***
}

\begin{abstract}
This study investigates ultimate stability strength behaviors of cylindrical steel shell panels under various types of uniaxial compression using the non-linear finite element procedure for the ultimate strength determination of shell-type-plate. The effects of residual stress and initial geometric imperfection are all included in the analysis. The numerical calculation method is verified and compared with previous theoretical works. Based on the investigation results, a practical formulation for the ultimate strength is also proposed.

Key Words : steel plate, shell, stability, ultimate strength, envelop
\end{abstract}

\section{INTRODUCTION}

There have recently been many investigations into nonlinear behavior of cylindrical steel panels under edge-loads ${ }^{1)-4}$. Those previous works were only concerned with the panels under pure compression $^{1)}$ or bending ${ }^{2) \sim 4}$. However, steel thin plate panels of cylindrical shell-type under edgeloads combined by uniform compression and bending component are important elements of spacial arch ribs and/or box girders with various cross sections. In considering limit state of those, the ultimate stability strength of the panels affects strongly. Neverthless, it is not sufficiently clear yet.

In this paper, the ultimate stability strength behaviors of cylindrical steel shell panels with residual stresses and initial imperfections under various compression, i.e., edge-loads combined by uniform compression and bending component are investigated by a nonlinear finite element approach using isoparametric shell model as shown in Fig.1 developed for determination of the ultimate strength of shell type plate ${ }^{5), 6}$. The method of analysis is verified and compared with previous theoretical works ${ }^{7,8)}$. The exact behavior of thin walled structural members, subject to buckling loads, is still beyond present approach. Considering simplifications may be made by treating the member as an assemblage of individual shell panel

* Member of JSCE, Dr. Eng., Professor, Department of Civil Engineering, University of Ryukyu, Okinawa, Japan.

** Member of JSCE, Dr. Eng., Research Associate, Department of Civil Engineering, University of Ryukyu.

*** M. Eng., former graduate student of University of Ryukyu, Yokogawa Bridge Co., Sakai, Osaka, Japan.

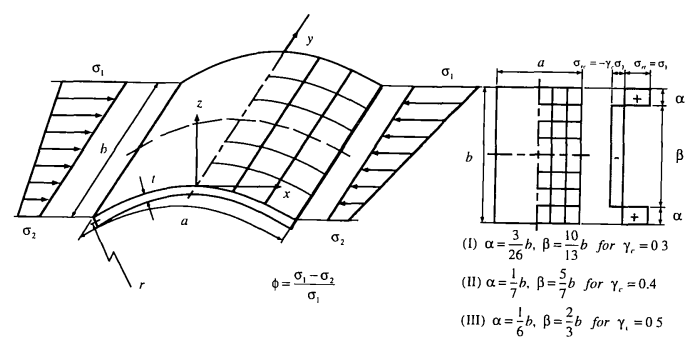

$\begin{array}{ll}\text { (a) Edge-loading and mesh model } & \text { (b) Residual stress model }\end{array}$

Fig.1 Cylindrical Shell Panel Model

elements simply loaded and supported along their mutual edges. The simplest stress system that can be applied to such elements is that of uniaxial inplane compressive loading in longitudinally flattened direction as shown in Fig.1 and it gives conservative evaluation for instability of the elements. It might be suitable for tracing the buckling behavior of the structural members that so-called follow forcing is applied to the elements. However, the external restrictions exerted to the elements for this forcing cause unreal behavior, which is inconceivable in the structural members subject to buckling loads. Therefore, herein, the abovementioned simplest stress system is adopted. This paper concentrates specifically on cylindrical shell panel with the residual stress caused by welding as shown in Fig. 1 assumed in the Merrison rules ${ }^{9}$ under nonuniform loading. Futhermore, the paper is concerned with the practical prediction of the complete collapse of the panel elements. The practical prediction is formulated using the envelop of resulting curves based on numerous data for the ultimate strengths of the panels parametrically calculated. The work is intended to be of direct practical suitable to the thin-walled, steel-plated, 
box sections of arch ribs and/or of girders with various sections.

\section{ANALYSIS METHOD}

\section{( 1 ) Updated Lagrangian Formulation}

Isoparametric shell elements are used for the present work and the element formulations are based on general incremental equations derived from Updated Lagrangian continum mechanics. By assuming perfect satisfaction of equilibrium in previous increments, the virtual work principle expressing the equilibrium and compatibility requirements of the element at the current load increment in the Updated Lagrangian formulation is given as follows :

$$
\int_{\nu(n)} S_{i j}^{(n+1)} \delta \Delta \varepsilon_{i j} d V^{(n)}=R^{(n+1)}
$$

where $R^{(n+1)}$ is the external virtual work and $\delta$ means variation operator, the $S_{i j}^{(n+1)}$ and the $\Delta \varepsilon_{i j}$ are the components of the 2 nd Piola-Kirchhoff stress tensor and Green-Lagrangian strain tensor (both referred to the deformation stage in the previous increments), as follows respectively:

$$
S_{i j}^{(n+1)}=\sigma_{i j}^{(n)}+\Delta S_{i j}, \Delta \varepsilon_{i j}=\Delta \varepsilon_{i j}^{L}+\Delta \varepsilon_{i j}^{N} \cdots(2 . \mathrm{a}, \mathrm{b})
$$

in which $\sigma_{i j}^{(n)}=$ Cauchy's stress in the previous increments ; $\Delta S_{i j}=$ the increment in the previous stress. Further, $\Delta \varepsilon_{i j}^{L}, \Delta \varepsilon_{i j}^{N}$ are the linear and nonlinear parts of the strain increments, respectively. They are defined as follows :

$$
\begin{aligned}
& \Delta \varepsilon_{i j}^{L}=\frac{1}{2}\left(\Delta u_{i j}+\Delta u_{j i}\right), \\
& \Delta \varepsilon_{i j}^{N}=\frac{1}{2} \Delta u_{k i} \cdot \Delta u_{k j}, \Delta u_{i j}=\frac{\partial \Delta u_{i}}{\partial x_{j}^{(n)}} \cdots \cdots \cdot(3 . \mathrm{a}, \mathrm{b}, \mathrm{c})
\end{aligned}
$$

where $\Delta u_{i}=$ the increments of displacements ; $x_{j}^{(\mathrm{n})}$ $=$ Cartesian local coordinate of any point in the element at the previous increments shown in Fig.2.

The material property is modified by elasticperfectly plastic model. The incremental stressstrain relationship for the material under going plastic flow is approximated using the von Mises yield criterion with its associated the Prandtl-Reuss flow rule. The von Mises yield criterion states that the following inequality holds for any for the stress state in the reference elements:

$$
\begin{aligned}
f= & \frac{1}{2}\left[\sigma_{11}^{2}+\sigma_{22}^{2}+\left(\sigma_{11}-\sigma_{22}\right)^{2}\right. \\
& \left.+6\left(\sigma_{12}^{2}+\sigma_{23}^{2}+\sigma_{32}^{2}\right)\right] \leq \sigma_{Y}^{2} .
\end{aligned}
$$

where $\sigma_{Y}=$ the uniaxial yield stress $; \sigma_{i i}=$ direct stress components in the $i$-direction $; \sigma_{i j}=$ the shear $i j$ stress. The incremental stress-strain equations can be expressed as :

$$
\Delta S_{i j}=D^{(n)} \Delta \varepsilon_{i j}
$$

where $D=D_{e}$ for elastic state ; $D=D_{p}$ for elasto-

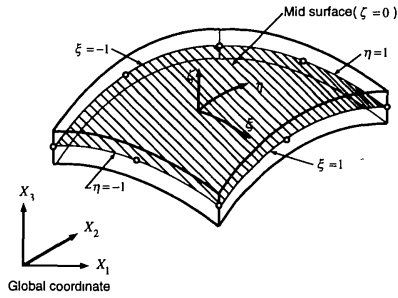

Fig.2 Reference Isoparametric Shell Element

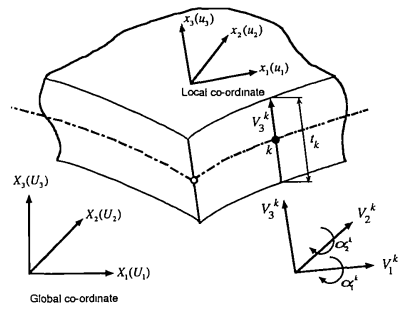

Fig.3 Definition of Vectors

plastic state. Using the Prandtl-Reuss flow rules, the equivalent elasto-plastic moduli $D_{p}$ can be defined as follows :

$$
\left[D_{p}\right]=\left[D_{e}\right]-\frac{\left[D_{e}\right]\{\partial f / \partial \sigma\}\{\partial f / \partial \sigma\}^{T}\left[D_{e}\right]}{H^{\prime}+\{\partial f / \partial \sigma\}^{T}\left[D_{e}\right]\{\partial f / \partial \sigma\}}
$$

where $H^{\prime}=$ the effective strain hardening modulus.

Substituting Eqs.(2), (3) and (5) into Eq.(1), the equilibrium equations in the current load increments are obtained:

$$
\left.\begin{array}{l}
\int_{\nu(n)} D^{(n)} \Delta \varepsilon_{i j}^{L} \delta \Delta \varepsilon_{i j}^{L} d V^{(n)}+\int_{\nu(n)} \sigma_{i j}^{(n)} \delta \Delta \varepsilon_{i j}^{N} d V^{(n)} \\
=R^{(n+1)}-\int_{\nu(n)} \sigma_{i j}^{(n)} \delta \Delta \varepsilon_{i j}^{L} d V^{(n)}
\end{array}\right\}
$$

(2) Finite Element Formulation

Isoparametric shell elements are used to obtain the finite element solution schemes for the element. Referring to Figs.2 and 3, the geometry of the variable number nodes in the shell element at the previous increments is interpolated as follows :

$$
\begin{aligned}
X_{i}^{(n)}= & \sum_{k=1}^{8} N_{k}(\xi, \eta)^{(n)} X_{i, k} \\
& +\sum_{k=1}^{8} N_{k}(\xi, \eta)^{(n)} \frac{t_{k}}{2} \zeta^{(n)} V_{3 i, k}^{(n)} .
\end{aligned}
$$

where $X_{i}^{(n)}=$ Cartesian global coordinate of any point in the element at the previous increments; $N_{k}(\xi, \eta)^{(n)}=$ isoparametric interpolation functions defined by the isoparametric element coordinates $\xi, \eta ; X_{i, k}=X_{i}^{(n)}$ of nodal point $k ; t_{k}=$ thickness of plate at nodal point $k ; V_{3 i k}^{(n)}=$ component $i$ of unit normal vector, $V_{3, k}$ to the surface of the plate at nodal $k$ in the previous increments. Substituing 
$\Delta \alpha_{1 k}^{(n)}$ and $\Delta \alpha_{2 k}^{(n)}$ be the rotations of the normal vectors about the vector $V_{1, k}$ and $V_{2, k}$ from the configuration at the previous increments to the configuration at the current increments into Eq.(8), the increments in the previous values of displacements are defined as follows:

$$
\begin{aligned}
& \Delta U_{i}^{(n)}=\sum_{k=1}^{8} N_{k}(\xi, \eta)^{(n)} \Delta U_{i, k}^{(n)}+ \\
& \sum_{k=1}^{8} N_{k}(\xi, \eta)^{(n)} \frac{t_{k}}{2} \zeta^{(n)}\left(V_{1 i, k}^{(n)} \Delta \alpha_{2, k}^{(n)}\right. \\
& \left.-V_{2 i, k}^{(n)} \Delta \alpha_{1, k}^{(n)}\right)
\end{aligned}
$$

The usual assumption for shell-element theory is now made that the element is in a state of stress condition $\left(\varepsilon_{33}=\right.$ normal strain in the direction of the shell thickness $=0)$. Thus, substituing Eq. (9) into Eqs.(2) and (3) yields :

$$
\begin{aligned}
& \Delta \varepsilon_{i j}=\left\{\Delta \varepsilon_{11}, \Delta \varepsilon_{22}, \Delta \varepsilon_{12}, \Delta \varepsilon_{23}, \Delta \varepsilon_{31}\right\} \\
& =\left\{\Delta \varepsilon_{i j}^{L}\right\}+\left\{\Delta \varepsilon_{i j}^{N}\right\} \\
& =\left[A_{0}\right]\{\Delta \theta\}+\left[A_{\theta}\right]\{\Delta \theta\} \\
& \{\Delta \theta\}=\left\{\Delta u_{11}, \Delta u_{21}, \Delta u_{31}, \Delta u_{12}, \Delta u_{22}\right. \text {, } \\
& \left.\Delta u_{32}, \Delta u_{13}, \Delta u_{23}, \Delta u_{33}\right\}^{T}
\end{aligned}
$$

The matrix $\left[A_{0}\right]$ and $\left[A_{\theta}\right]$ are shown in the APPENDIX. The displacement derivatives corresponding to the global coordinate system can be obtained by employing the Jacobian transformation :

$$
\begin{aligned}
& {\left[\begin{array}{l}
\frac{\partial \Delta u_{1}}{\partial x_{1}}, \frac{\partial \Delta u_{2}}{\partial x_{1}}, \frac{\partial \Delta u_{3}}{\partial x_{1}} \\
\frac{\partial \Delta u_{1}}{\partial x_{2}}, \frac{\partial \Delta u_{2}}{\partial x_{2}}, \frac{\partial \Delta u_{3}}{\partial x_{2}} \\
\frac{\partial \Delta u_{1}}{\partial x_{3}}, \frac{\partial \Delta u_{2}}{\partial x_{3}}, \frac{\partial \Delta u_{3}}{\partial x_{3}}
\end{array}\right]} \\
& =[T]^{T}[J]^{-1}\left[\begin{array}{l}
\frac{\partial \Delta U_{1}}{\partial \xi}, \frac{\partial \Delta U_{2}}{\partial \xi}, \frac{\partial \Delta U_{3}}{\partial \xi} \\
\frac{\partial \Delta U_{1}}{\partial \eta}, \frac{\partial \Delta U_{2}}{\partial \eta}, \frac{\partial \Delta U_{3}}{\partial \eta} \\
\frac{\partial \Delta U_{1}}{\partial \zeta}, \frac{\partial \Delta U_{2}}{\partial \zeta}, \frac{\partial \Delta U_{3}}{\partial \zeta}
\end{array}\right][T]
\end{aligned}
$$

where $[J]=$ Jacobian matrix $;[T]=$ transformation matrix. Substituing Eq.(9) into Eq.(11) yields :

$$
\{\Delta \theta\}=\sum_{k=1}^{8}\left[G_{k}\right]\{\Delta \bar{U}\}
$$

where

$$
\begin{aligned}
& {\left[G_{k}\right]=\left[\left[B_{k}\right][T]^{T}, \frac{t_{k}}{2}\left[C_{k}\right][T]^{T}\left[\Phi_{k}\right]\right],} \\
& \{\Delta \bar{U}\}=\left\{\Delta U_{1, k}, \Delta U_{2, k}, \Delta U_{3, k}, \Delta \alpha_{1, k}, \Delta \alpha_{2, k}\right\}, \\
& {\left[\Phi_{k}\right]=\left[V_{1, k},-V_{2, k}\right] \ldots \ldots \ldots \ldots \ldots \ldots \ldots(13 . \mathrm{a}, \mathrm{b}, \mathrm{c})}
\end{aligned}
$$

The matrixes $\left[B_{k}\right]$ and $\left[C_{k}\right]$ are shown in the APPENDIX. Substituing Eq.(12) into Eq.(10), the derivation in the elastic and plastic parts of the strain increments can be rewritten as follows:

$$
\begin{aligned}
\delta\left\{\Delta \varepsilon_{i j}^{L}\right\}= & \sum_{k=1}^{8}\left[B_{k}^{L}\right] \delta\{\Delta \bar{U}\}, \\
\delta\left\{\Delta \varepsilon_{i j}^{N}\right\}= & \frac{1}{2} \sum_{k=1}^{8} \delta\left[A_{\theta}\right]\left[G_{k}\right]\{\Delta \bar{U}\} \\
& +\frac{1}{2} \sum_{k=1}^{8}\left[A_{\theta}\right]\left[G_{k}\right] \delta\{\Delta \bar{U}\} \cdots \cdots(14 . \mathrm{a}, \mathrm{b})
\end{aligned}
$$

where

$$
\left[B_{k}^{L}\right]=\left[\left[H_{k}\right][T]^{T}, \frac{t_{k}}{2}\left[L_{k}\right][T]^{T}\left[\Phi_{k}\right]\right] \cdots
$$

The matrix $\left[H_{k}\right]$ and $\left[L_{k}\right]$ are shown in the APPENDIX. From Eqs.(7) and (14), the following incremental stiffness equation can be derived, eventually :

$$
\left[K^{(n)}\right]\{\Delta \bar{U}\}=\left\{F_{e x t}^{(n+1)}\right\}-\left\{F_{\text {int }}^{(n)}\right\}
$$

where $\left[K^{(n)}\right]=$ the tangent stiffness matrix; $\left\{F_{e x t}^{(n+1)}\right\}=$ an external load vector at the current increments; $\left\{F_{\text {int }}^{(n)}\right\}=$ an internal load vector to be a function of the current stress resultants. The tangent stiffness $\left[K^{(n)}\right]$ is dependent on the current stress resultants, the current configurations and the current elasto-plastic moduli as follows :

$$
\left.\begin{array}{rl}
{\left[K^{(n)}\right]=} & \int_{-1}^{1} \int_{-1}^{1} \int_{-1}^{1}\left[B_{i}^{L}\right]^{T}\left[D_{e}\right]\left[B_{j}^{L}\right][J] d \xi d \eta d \zeta \\
& +\int_{-1}^{1} \int_{-1}^{1} \int_{-1}^{1}\left[G_{i}\right]^{T}[\sigma]\left[G_{j}\right][J] d \xi d \eta d \zeta
\end{array}\right\}
$$

where

$$
[\sigma]=\left[\begin{array}{ccc}
\sigma_{11}[I] & \sigma_{12}[I] & \sigma_{13}[I] \\
& \sigma_{22}[I] & \sigma_{23}[I] \\
\text { sym. } & & \sigma_{33}[I]
\end{array}\right]
$$

\section{(3) Numerical Solution Technique}

The elasto-plastic moduli are calculated using a rigorous multi-layer approach based on the usual Gauss integration $(\xi, \eta, \zeta=2 \times 2 \times 5)$, and these are formed by numerical integration. The governing equations of equilibrium are solved numerically, using an incremental displacement method combined with Newton-Raphson iteration. Assuming that the element is not subjected to any external loads excepting at the mesh points under the applied, enforced displacments $\left(\left\{\Delta f_{a}^{(n)}\right\}=0\right)$, the incremental stiffness equations can be expressed as follows :

$$
\left[\begin{array}{cc}
K_{a a}^{(n-1)} & K_{a b}^{(n-1)} \\
K_{b a}^{n-1)} & K_{b b}^{(n-1)}
\end{array}\right]\left\{\begin{array}{c}
\Delta \bar{U}_{a}^{(n)} \\
\Delta \bar{U}_{b}^{(n)}
\end{array}\right\}=\left\{\begin{array}{c}
\Delta f_{a}^{(n)} \\
\Delta f_{b}^{(n)}
\end{array}\right\}+\left\{\begin{array}{l}
R_{a}^{(n-1)} \\
R_{b}^{(n-1)}
\end{array}\right\}
$$

where $\left\{\Delta \bar{U}_{a}^{(n)}\right\}=$ the unknown increments of dis- 
placements $;\left\{\Delta \bar{U}_{b}^{(n)}\right\}=$ the applied, enforced displacements; $\left\{\Delta f^{(n)}\right\}=$ the increments of loads; $\left\{R^{(n-1)}\right\}=$ the out of balance load vectors (i.e., unbalanced force residuals). Thus, from Eq.(19), the unknown incremental displacements can be solved as follows :

$$
\begin{aligned}
\left\{\Delta \bar{U}_{a}^{(n)}\right\}= & {\left[K_{a a}^{(n-1)}\right]^{-1}\left(\left\{R_{a}^{(n-1)}\right\}\right.} \\
& \left.-\left[K_{a b}^{(n-1)}\right]\left\{\Delta \bar{U}_{b}^{(n)}\right\}\right)
\end{aligned}
$$

The unbalanced force residuals vanish if the external and internal forces are in exact equilibrium at the onset of the external increment. The inclusion of the unbalanced force residuals in Eq.(20) enables Newton-Raphson iterations until the convergence criteria are met. A solution is regarded as converged when each norm ratio for the incremental displacements and for the unbalanced force residuals is within the tolerance of $e_{1}=$ 0.001 . The norm ratio is defined as a ratio of norm of incremental values to the norm of total ones in an increment. Thus :

$$
\left\|\Delta \bar{U}^{(n)}\right\| /\left\|\sum \Delta \bar{U}\right\| \leq e_{1},\left\|\Delta R^{(n)}\right\| /\left\|\sum \Delta f\right\| \leq e_{1} \cdots(21)
$$

The lack of equilibrium for the shell element is associated with the residual stresses adopted herein as shown in Fig.1. Before any incrementing is applied to the shell panel, iterations are made to eliminate this lack. These initial iterations cause some residual deformation to the panel element and the deformed configulation, in general, is not equal to a desired initial imperfection as shown in Fig.4. Herein, the desired initial imperfection is given as :

$$
w_{0}=\bar{w}_{0} \cos \frac{\pi x}{a} \sin \frac{\pi y}{b}
$$

Thus, a renewed initial crookedness, $w_{\text {renewal }}$, given by subtracting the total residual deformation, $w_{\text {residual }}$, as shown in Fig.4, from the desired initial imperfection is considered as follows :

$$
w_{\text {renewal }}=2 w_{0}-w_{\text {residual }}
$$

Then, the iterations are renewedly made. This treatment process is repeated until $w_{\text {residual }}$ becomes equal to $w_{0}$, i.e., the desired initial imperfection given by Eq. (22.a) is ensured in the panel element. Fig.5 shows typical result on the renewed initial crookedness after abovementioned treatment. The curves show that the desired initial imperfection is eventually ensured by the adopted approach.

Here the load is applied by incrementing displacement which corresponds to the desired loading.

\section{COMPARISON WITH PREVIOUS WORKS}

The writers could not find in the literature any

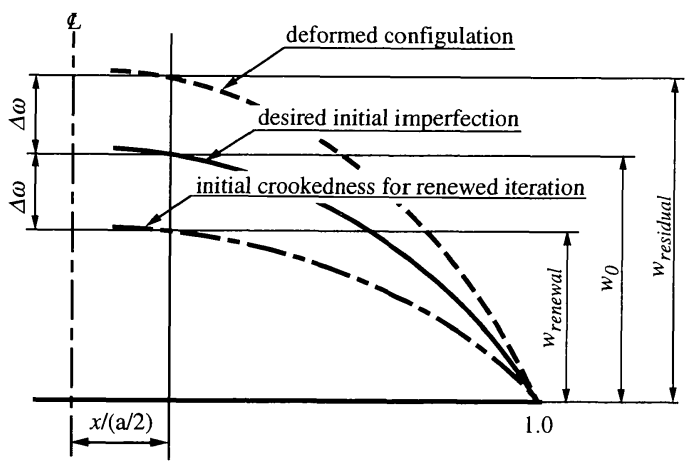

Fig.4 Initial Crookedness in Initial Iterations

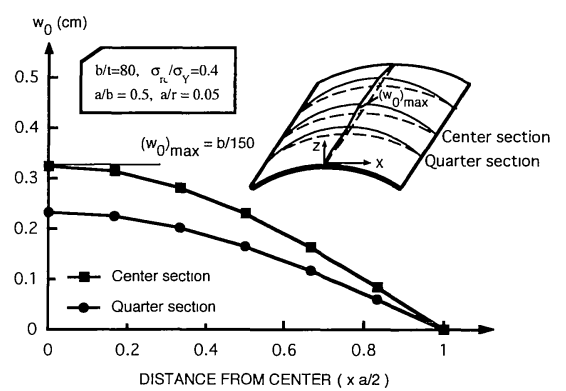

Fig.5 Initial Crookedness

experimental studies of shell panels under nonlinear behavior. The adopted method was therefore applied to analyze recently available theoretical works on nonlinear behavior for shell panel elements. First is the geometrical nonlinear behavior for a cylindrical shell ${ }^{7}$ as shown in the inset of Fig.6. The longitudinal boundaries of the shell are hinged and inmovable, whereas the circular edges are completely free. Considering the symmetric behavior of the shell panel, a nineelement model for the quarter shell is adopted. The load is applied by incrementing the enforced displacement at the center of the shell. The figure of the load-deflection curve is shown in Fig.6. As obvious from Fig.6, the result obtained here shows good agreement with that previously reported and recognized in Reference ${ }^{7}$. Next is the material and geometrical nonlinear behavior for a simply supported, initially unflatted plate ${ }^{8)}$ with the residual stress under uniaxial compression as shown in the inset of Fig.7. The self-equilibrating form of the residual stresses applied during the welding process is considered as shown in the inset of Fig.7. The initial imperfection adopted is an doubly sinusoidal. These are all the same as Little's example. Considering the symmetric behavior of the unflatted plate, a twelve-element model for the quarter shell is adopted. The material is mild steel $\sigma_{Y}=250 \mathrm{MPa}, E=205 \mathrm{GPa}, \nu=0.3$. The comparison is performed for the plates having a thickness 
Table 1 Panel Parameters and Their Ranges Selected in the Study

\begin{tabular}{c|c|c}
\hline \hline $\begin{array}{c}\text { Item } \\
(1)\end{array}$ & $\begin{array}{c}\text { Symbol } \\
(2)\end{array}$ & $\begin{array}{c}\text { Range of values } \\
(3)\end{array}$ \\
\hline Aspect ratio & $\mathrm{a} / \mathrm{b}$ & $0.5,0.75,1.00,1.25$ \\
Width-to-thickness ratio & $\mathrm{b} / \mathrm{t}$ & $\begin{array}{l}\phi=0 ; 30,40,55,80 \\
\phi=1 ; 40,55,80,110 \\
\phi=2 ; 60,90,120,160\end{array}$ \\
\hline Initial imperfection & $\bar{w}_{0}$ & $0.0, \mathrm{~b} / 150$ \\
\hline Yield stress parameter & $E / \sigma_{Y}$ & 875,656 \\
\hline Residual compressive stress & $\sigma_{r c} / \sigma_{Y}$ & $0.0,0.3,0.4,0.5$ \\
\hline Shell curvature angle & $\mathrm{a} / \mathrm{r}$ & $0.0,0.01,0.025,0.05$ \\
\hline Stress inclination & $\phi$ & $0,1,2$ \\
\hline \hline
\end{tabular}

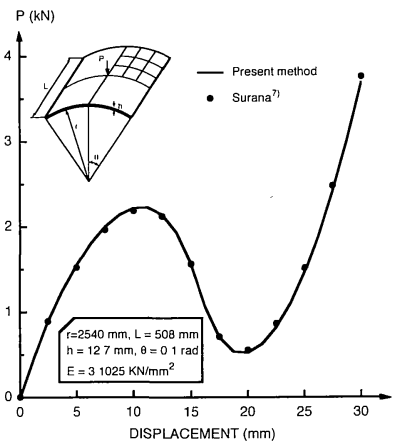

Fig.6 Comparison of An Available Theoretical Solution by Surana

of $t=8 \mathrm{~mm}$, an aspect ratio of $a / b=0.875$, and various $b / t$ ratios of $30,40,55,80$. These properties are all the same as Little's work. Again, the finite element solutions obtained here are in close agreement with the solutions reported and recognized by Little.

\section{PARAMETRIC STUDY}

Data presented herein are using numerical model for each panel illustrated in Fig.1. The panel parameters and their ranges are selected in the study as given in Table 1. The ranges of these parameters are generally within found in steel arch and/or girder bridges. Initial imperfection with $\bar{w}_{0} / b$ $=1 / 150$ of out of plane specified in JSHSB $^{10)}$ is defined as follows :

$$
w_{0}=\bar{w}_{0} \cos \frac{\pi x}{a} \sin \frac{\pi y}{b} \text {. }
$$

and is considered for each panel. The panel element has boundary restraint as constrained transverse boundaries to remain straight at loading edges and longitudinal boundaries to remain its original curvatures at free loading edges. This is an approximation of the boundary condition for a panel in box section of the arch rib and/or girder. Conventional stress blocks assumed for residual

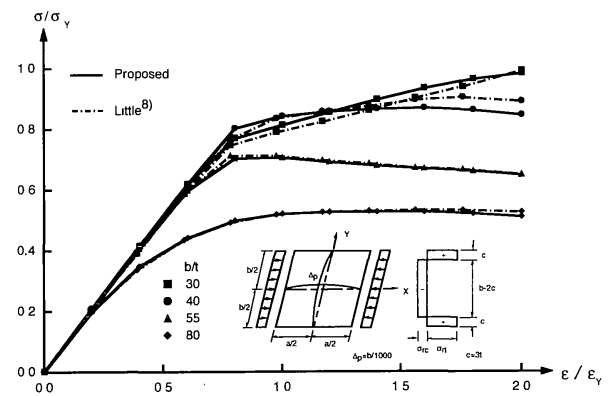

Fig.7 Comparison of An Available Theoretical Solution by Little

stresses in the Merrison rules ${ }^{9)}$ is adopted as shown in Fig.1. Experimental results previously for thinner plates ${ }^{11)}$ have dictated that the pattern of residual stress has a maximum stress in tension equal to the yield stress of material, $\sigma_{Y}$, and the stress in compression equal to $40 \%$ of $\sigma_{Y}$ and this dictation is adopted here, also ${ }^{12}$. By referring the results of preexamination ${ }^{5)}$, the quarter-panel is meshed with twelve-elements (three for longitudinal and four for transverse) for uniform compression and the half-panel meshed with eighteenelements (three for longitudinal and six for transverse) for nonuniform compression.

\section{(1) Load-Deformation Curve}

A typical deflection mode is shown in Fig.8. In order to grasp load-deformation curves for the panels, the curves are analyzed for various panels with standard initial imperfection and residual stresses. Some selected results are given in Figs.9, 10 and 11. The curves shown relate the load as a resultant by stress distribution at loading edges of the panel, nondimensionalized with respect to elastic limit load, to the corresponding displacement as the resultant by the applied strain on the panel, nondimensionalized by the elastic limit displacement. From the results on the load- 


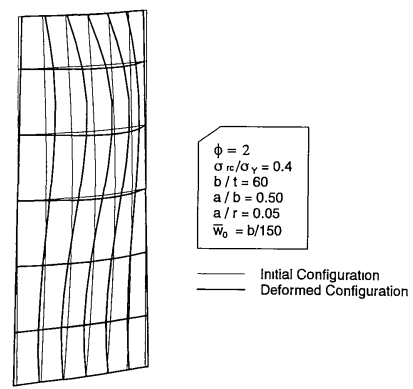

Fig.8 Typical Deformation Mode $(\phi=2)$

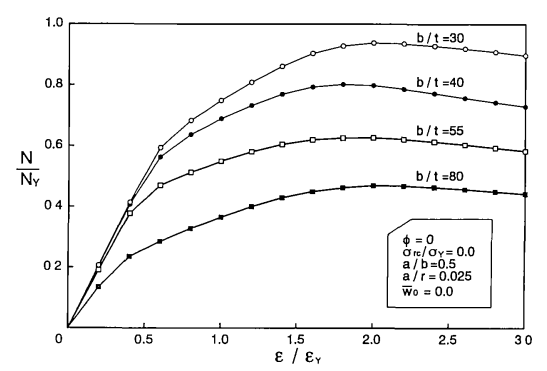

Fig.9 Load-Deformation Curves $\left(N / N_{Y}-\varepsilon / \varepsilon_{Y}, \sigma_{r c}=0\right)$

deformation relationships, it seems to cause a tendency whose a slender panel leads to a load-deformation curve slightly falling to a plateau over its peaking. Hereafter, the ultimate stength is defined at a peak of a load-deformation curve.

\section{(2) Effect of Aspect Ratio}

Fig.12 presents relationship between the ultimate stress, $\sigma_{\max , 1 s t}$ and aspect ratio, $a / b$, for three different compression patterns $(\phi=0,1,2)$, where the ultimate stress is defined by multiplying Young's modulus, $E$, to average strain for $\phi=0$ and maximum compression strains for $\phi=1$ and 2, at loading edges respectively. Table 2 also shows the relationships for various values of the aspect ratio, $a / b$ and width-to-thickness ratio, $b / t$ subject to various compressions. It is clear that the lowest failure loads generally occur with an aspect ratio less than unity. At the certain value, 0.5 of the aspect ratio, the ultimate load of the panel is merged into the lowest mean load over the full ranges of $b / t$ and $a / b$ ratios, except the case of $b / t=$ 55 for $\phi=0$. Although the ultimate stress for the width-to-thickness ratio, $b / t=55$ under pure compression, $\phi=0$ varies with the aspect ratio $a / b$, the collapse load is fairly insensitive to the aspect ratio as shown in Table 2. Therefore, the critical aspect ratio of $a / b=0.5$ is used in the parametric study.

\section{(3) Effects of Initial Imperfections}

Some selected results of the effects of the initial

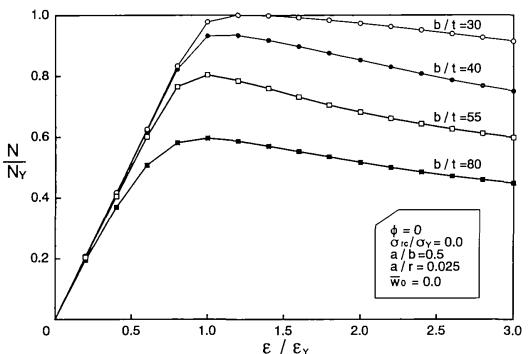

Fig.10 Load-Deformation Curves $\left(N / N_{Y}-\varepsilon / \varepsilon_{Y}, \sigma_{r c} / \sigma_{Y}\right.$ $=0.4)$

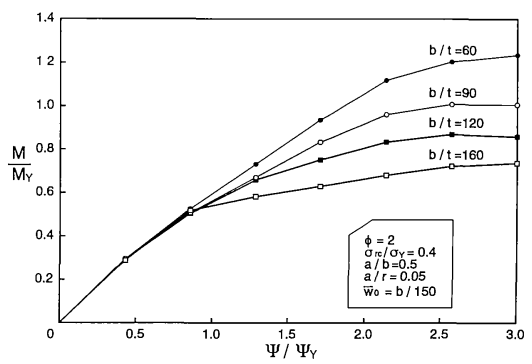

Fig.11 Load-Deformation Curves $\left(M / M_{Y}-\Psi / \Psi_{Y}\right)$

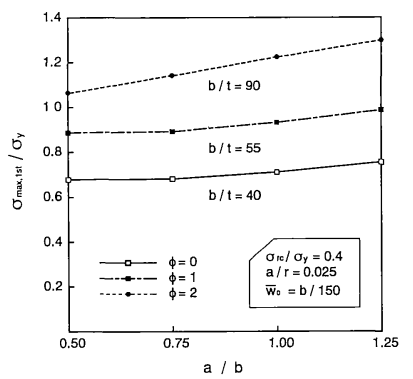

Fig.12 Relationship Between the Ultimate Stress, $\sigma_{\max , 1 s t}$, and Aspect Ratio, $a / b$

imperfection on the ultimate strengths are shown in Table 3 where the ultimate strengths are the nondimensional maximum edge loads of the reference panels with $\sigma_{r c} / \sigma_{Y}=-0.4$ and various values of $a / r$ and $b / t$, under uniform compressing. In the table, $\bar{w}_{0} / b=1 / 150$ is the tolerance limit of fabrication imperfection specified by the JSHSB. As obvious from the table, the ultimate strength without the initial imperfection is higher than that with it, in all cases. The percentage of difference in the two increases as decrease of $a / r$ and/or $b / t$.

\section{(4) Effects of Residual Stresses}

The effect of the residual stress on the ultimate strength is checked by varying the compression component in the residual stress distribution. The typical results on the shell panel with $a / r=0.025$ 
Table 3 Results of $\sigma_{\max , 1 s t} / \sigma_{Y}$ for Various Values of $a / r$, $\bar{w}_{0}, b / t$

\begin{tabular}{c|c|c|c|c|c}
\hline \hline \multirow{2}{*}{$\begin{array}{c}\mathrm{a} / \mathrm{r} \\
(1)\end{array}$} & \multirow{2}{*}{$\begin{array}{c}\bar{w}_{0} \\
(2)\end{array}$} & $\begin{array}{c}30 \\
(3)\end{array}$ & $\begin{array}{c}40 \\
(4)\end{array}$ & $\begin{array}{c}55 \\
(5)\end{array}$ & $\begin{array}{c}80 \\
(6)\end{array}$ \\
\cline { 3 - 6 } & 0.0 & 0.989 & 0.848 & 0.652 & 0.485 \\
\hline \multirow{2}{*}{0.01} & $\mathrm{~b} / 150$ & 0.811 & 0.698 & 0.580 & 0.453 \\
\cline { 2 - 6 } & 0.0 & 0.938 & 0.802 & 0.627 & 0.469 \\
\cline { 2 - 6 } & $\mathrm{b} / 150$ & 0.788 & 0.677 & 0.562 & 0.438 \\
\hline \multirow{2}{*}{0.05} & 0.0 & 0.877 & 0.743 & 0.592 & 0.446 \\
\cline { 2 - 6 } & $\mathrm{b} / 150$ & 0.751 & 0.645 & 0.532 & 0.414 \\
\hline \multicolumn{7}{|c|}{ Note $: \phi=0, a / b=0.5, \sigma_{r c} / \sigma_{Y}=-0.4$} \\
\hline
\end{tabular}

Table 2 Results of $\sigma_{\max , 1 s t} / \sigma_{Y}$ for Various Values of $\phi$, $b / t, a / b$

\begin{tabular}{|c|c|c|c|c|c|}
\hline \multirow[b]{2}{*}{$\begin{array}{l}\phi \\
(1)\end{array}$} & \multirow{2}{*}{$\begin{array}{l}\mathrm{b} / \mathrm{t} \\
\text { (2) }\end{array}$} & \multicolumn{4}{|c|}{$a b b$} \\
\hline & & $\begin{array}{l}0.5 \\
\text { (3) }\end{array}$ & $\begin{array}{l}0.75 \\
(4)\end{array}$ & $\begin{array}{l}10 \\
\text { (5) }\end{array}$ & $\begin{array}{l}125 \\
(6) \\
\end{array}$ \\
\hline \multirow{4}{*}{0} & 30 & 0.788 & 0.799 & 0.845 & 0.900 \\
\hline & 40 & 0.677 & 0680 & 0.709 & 0.754 \\
\hline & 55 & 0.562 & 0.558 & 0.575 & 0.600 \\
\hline & 80 & 0438 & 0.441 & 0457 & 0.475 \\
\hline \multirow{4}{*}{1} & 40 & 1072 & 1.093 & 1.146 & 1221 \\
\hline & 55 & 0.887 & 0.891 & 0932 & 0986 \\
\hline & 80 & 0689 & 0.699 & 0727 & 0.766 \\
\hline & 110 & 0.582 & 0.606 & 0.622 & 0.720 \\
\hline \multirow{4}{*}{2} & 60 & 1.292 & 1363 & 1.406 & 1.426 \\
\hline & 90 & 1065 & 1142 & 1224 & 1.298 \\
\hline & 120 & 0908 & 0.971 & 1.054 & - \\
\hline & 160 & 0.772 & 0.837 & 0.874 & - \\
\hline
\end{tabular}

are listed in Table 4 for $\phi=0$ loading with $b / t=55$, $\phi=1$ loading with $b / t=80$, and $\phi=2$ loading with $b / t=120$. It is clear from Table 4 that the ultimate strengths of the panels with the residual stress under $\phi=0,1$ decreases as increase of $\sigma_{r c}$, while the ultimate strength of the panel under $\phi=2$ increases. The difference in the ultimate strengths with and without the residual stress is remarkable, but that in the strengths with $\sigma_{r c} / \sigma_{Y}=-0.3,-0.4$ and -0.5 is very small.

( 5 ) Effects of Shell Curvature and Width-

\section{Thickness-Ratio Parameter}

Figs.13, 14 and 15 show typical dimensionless presentations of the panel strength results and panel slendernesses for $\phi=0,1,2$ and four different shell curvatures, $a / r=0,0.01,0.025$ and 0.05 , where $r=$ radius of curvature. The modified panel slenderness ratio, $R$, is defined as follows :

$$
R=\frac{1}{\pi} \sqrt{\frac{12\left(1-\nu^{2}\right)}{K}} \sqrt{\frac{\sigma_{Y}}{E}} \frac{b}{t} .
$$

where $\nu=$ Poisson's ratio, $K=$ elastic buckling coefficient of a plate with $a / r=0$ under edge loading; i.e., $K=4$ for $\phi=0,7.81$ for $\phi=1$, and 23.9 for $\phi=2$. In these figures, the elastic buckling curve for plane plates $(a / r=0)$ is also shown for
Table 4 Results of $\sigma_{\max , 1 s t} / \sigma_{Y}$ for Various Values of $\phi, \sigma_{r c} / \sigma_{Y}$

\begin{tabular}{c|c|c|c|c}
\hline \hline \multirow{2}{*}{$\phi$} & \multicolumn{4}{|c}{$\sigma_{r c} / \sigma_{r}$} \\
\cline { 2 - 5 }$(1)$ & 0 & -0.3 & -0.4 & -0.5 \\
$(2)$ & $(3)$ & $(4)$ & $(5)$ \\
\hline 0 & 0.619 & 0.570 & 0.562 & 0.553 \\
\hline 1 & 0.705 & 0.703 & 0.691 & 0.693 \\
\hline 2 & 0.891 & 0.906 & 0.908 & 0.914 \\
\hline$b / t=55$ for $\phi=0 ; b / t=80$ for $\phi=1 ; b / t=120$ for $\phi=2 ;$ \\
$a / b=0.5, \bar{w}_{0}=b / 150, a / r=0.025$
\end{tabular}

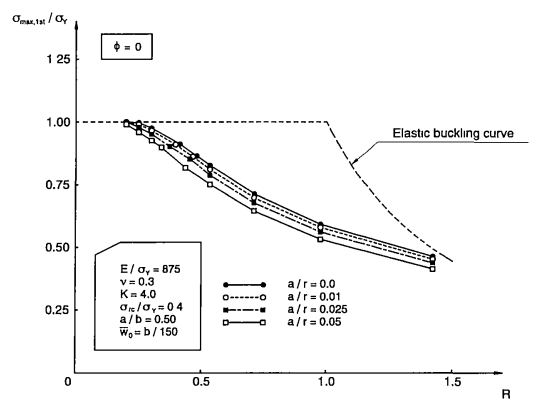

Fig.13 Typical Dimensionless Presentations of the Panel Strength Results and Panel Slendernesses for $\phi=0$

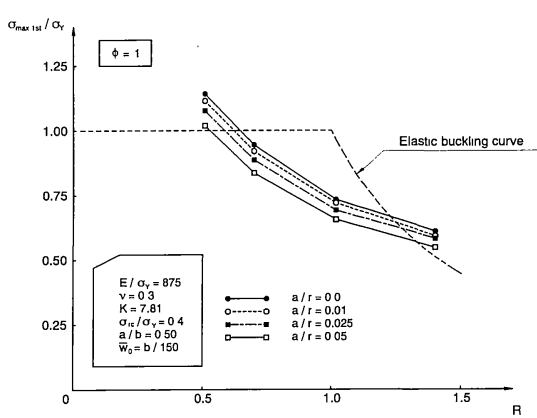

Fig.14 Typical Dimensionless Presentations of the Panel Strength Results and Panel Slendernesses for $\phi=1$

comparison purpose. A general conclusion that may be drawn from the parametric study for the influence of the shell curvatures is that the panel strength decreases as increase of $a / r$. The most interesting feature of these results is that the actual strength of the panel with large width-to-thickness ratio under a loading combined by uniform compression and bending component exceeds the elastic buckling strength, i.e., they exibit postbuckling strengths.

\section{PRACTICAL FORMULATION}

The extensive numerical results obtained from the study make the development of a practical formulation for determination of the ultimate 


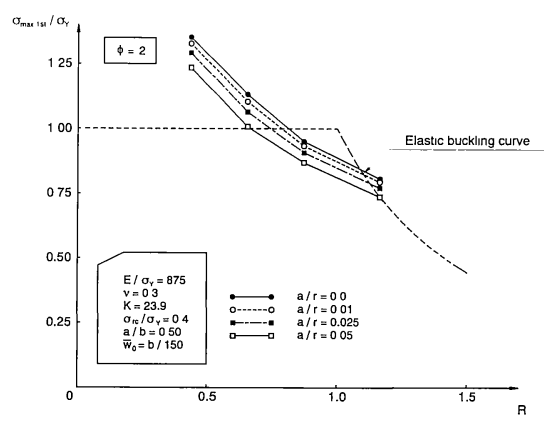

Fig.15 Typical Dimensionless Presentations of the Panel Strength Results and Panel Slendernesses for $\phi=2$

stability strength of the panels. The first step is to formulate a standard fitting curve for the analyzed ultimate strength results on the panels with $a / r=0$ for various of the modified panel slendernesses under the uniform compression $(\phi=0)$ as shown in Fig.16. As a result of curve-fitting for the calculated ultimate strengths, it is found that expressing the practical formulation in a term of coefficient of the exponent gives good prediction, given by:

$$
\left.\begin{array}{r}
\frac{\sigma_{\max , 1 s t}}{\sigma_{Y}}=\left(\frac{R_{c r, c}}{R}\right)^{0.592} \text { for } R \geq 0.6 \\
\frac{\sigma_{\max , 1 s t}}{\sigma_{Y}}=2.5\left(\bar{\sigma}_{0.6}-1\right) R-0.5 \bar{\sigma}_{0.6}+1.5 \\
\text { for } 0.2 \leq R \leq 0.6
\end{array}\right\}
$$

where $\bar{\sigma}_{0.6}=\left(R_{c r, c} / 0.6\right)^{0.592}$, and $R_{c r, c}$ is a critical modified slenderness ratio for a panel under the uniform compression as shown in Fig.16 and a ratio of 0.395 is given to the panel with $a / r=0$ by curve-fitting.

The second step is to establish the ultimate strength formula being applicable for the effect of shell curvature. Fig.17 shows the relationship between the shell curvature parameter, $a / r$, and the critical modified panel slenderness, $R_{c r, c}$, evaluated by the abovementioned curve-fitting approach. By applying a regression analysis on statistics, a prediction formula for the $R_{c r, c}$ can be obtained as follows :

$$
R_{c r, c}=0.395-1.08 a / r
$$

This formula is also shown in Fig.17. It is proposed to use the same $R_{c r, c}$ value to evaluate the effect of shell curvature on the ultimate strength.

The third step is to establish the ultimate strength formula being applicable for the effect of bending load component. A simple way of recognizing the bending component effect is to use so-called "effective width-to-thickness ratio concept", in which the stability strength of the

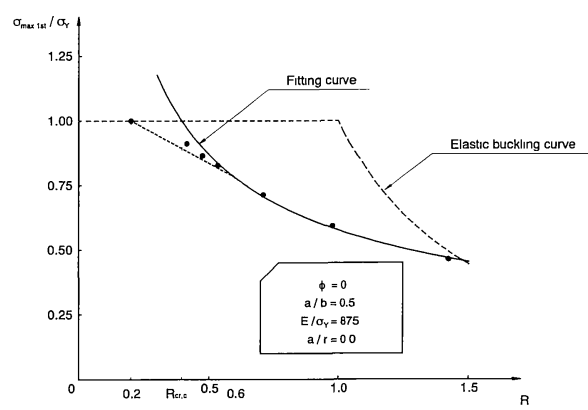

Fig.16 A Standard Fitting Curve for the Analyzed Ulitmate Strength Results on the Panels with $a / r$ $=0$

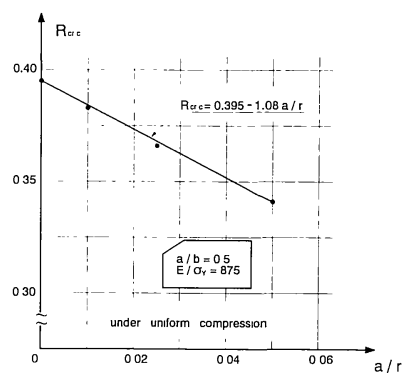

Fig.17 Relationship Between the Shell Curvature Parameter and the Critical Modified Panel Slenderness

panel under the combined loads is related to that of a panel with a reduced width-to-thickness ratio under the uniform compression. A factor of the reduced ratio, $f_{0}$, is defined as follows:

$$
f_{0}=\frac{R_{c r}}{R_{c r, c}} \sqrt{\frac{K}{K_{c}}}
$$

where $K_{c}$ is the elastic buckling coefficient of a plate with $a / r=0$ under the uniform compressive edge loading, i.e., $K_{c}=4$, and $R_{c r}$ is the critical modified slenderness for a panel under the combined loading. This $R_{c r}$ is evaluated by the aforementioned curve-fitting for various values of $\phi$ and $a / r$. The results are given in Table 5. Substituting $R_{c r}$ of those into Eq.(27), the $f_{0}$ is evaluated for various of $\phi$. Fig.18 presents $f_{0}-\phi$ relationships for a variety of $a / r$ parameters. The noticeable feature of these results is that the factor of the reduced width-to-thickness ratio, $f_{0}$, is not explicitly effected by the parameter of $a / r$. Namely, the parameter of $a / r$ in the $R_{c r, c}$ has implicit effects on the $f_{0}$. By applying the regression analysis to the $f_{0}-\phi$ relationships, a prediction formula for the $f_{0}$ can be obtained as follows :

$$
f_{0}=1+0.514 \phi+0.719 \phi^{2}
$$

This formula is also shown in Fig.18. It is proposed to use the $f_{0}$ formulated by Eq. (28) to evaluate the 
Table 5 Results of $R_{c r}$ and $f_{0}$

\begin{tabular}{c|c|c|c|c|c|c|c|c}
\hline \multirow{2}{*}{$\phi$} & \multicolumn{10}{c|}{$a / r$} \\
\cline { 2 - 10 } & \multicolumn{2}{|c|}{0} & \multicolumn{2}{|c|}{0.01} & \multicolumn{2}{c|}{0.025} & \multicolumn{2}{|c}{0.05} \\
\cline { 2 - 10 } & $R_{c r}$ & $f_{0}$ & $R_{c r}$ & $f_{0}$ & $R_{c r}$ & $f_{0}$ & $R_{c r}$ & $f_{0}$ \\
$(1)$ & $(2)$ & $(3)$ & $(4)$ & $(5)$ & $(6)$ & $(7)$ & $(8)$ & $(9)$ \\
\hline 0 & 0.395 & 1 & 0.383 & 1 & 0.366 & 1 & 0.341 & 1 \\
\hline 1 & 0.631 & 2.232 & 0.608 & 2.218 & 0.573 & 2.188 & 0.524 & 2.147 \\
\hline 2 & 0.792 & 4.901 & 0.764 & 4.876 & 0.721 & 4.815 & 0.658 & 4.717 \\
\hline \hline
\end{tabular}

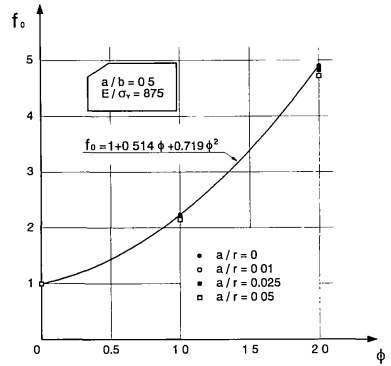

Fig.18 $f_{0}-\phi$ Relationships for a Variety of $a / r$ Parameters

effect of bending load component on the ultimate stability strength.

Therefore, Eq.(25) can be rewritten as being applicable for the cylindrical panels under the combined edge-loads, given by ;

$$
\begin{aligned}
& \frac{\sigma_{\mathrm{max}, 1 s t}}{\sigma_{Y}}=\left(\frac{R_{c r}}{R}\right)^{0.592} ; \\
& R_{c r}=f_{0} \cdot R_{c r, c} \cdot \frac{2}{\sqrt{K}} ; R_{c r, c}=0.395-1.08 \mathrm{a} / r ; \\
& f_{0}=1+0.514 \phi+0.719 \phi^{2} . \cdots \cdots \cdots \cdot(29 . \mathrm{a}, \mathrm{b}, \mathrm{c}, \mathrm{d})
\end{aligned}
$$

provided that :

for $0.2 \leq R \leq 0.6$ and $\phi=0$

$$
\begin{aligned}
& \frac{\sigma_{\max , 1 s t}}{\sigma_{Y}}=2.5\left(\bar{\sigma}_{0.6}-1\right) R-0.5 \bar{\sigma}_{0.6}+1.5 ; \\
& \bar{\sigma}_{0.6}=\left(R_{c r, c} / 0.6\right)^{0.592} \ldots \ldots \ldots \ldots \ldots \ldots \ldots \ldots
\end{aligned}
$$

These equations are, finally, proposed formula for the ultimate stability strength of cylindrical steel shell panels with residual stresses and initial imperfections under edge-loads combined by uniform compression and bending component. The accuracy of this formula in predicting the strength of panels is examined by the parametric study and partially demonstrated in Fig.19 for $\phi=0$, Fig.20 for $\phi=1$ and Fig.21 for $\phi=2$, and various of $a / r$. Fig.22 shows for $\phi=0,1,2$ and two sets of different yield stresses of material $E / \sigma_{Y}=875$ and 656 , respectively. The absolute values of differences between the results by the proposed prediction formula and by the ultimate strength analysis are gathering from 0.001 to 0.066 . The mean value and standard error are 0.021 and 0.003 . Therefore, it may be concluded from those results that the prediction formulas proposed by Eqs.(29) and (30) evaluate the ultimate stability strengths of the panels under the combined edge-loads accurately enough for practical purpose. The proposed formula is compared with other formulas for a simply supported plate under the uniform compression $^{1,13), 14,15)}$ as shown in Fig.23. From the Fig.23 it is seen that the proposed formula gives rather smaller strength than the other ones. This tendency may be caused by treating the lack of equilibrium associated with the residual stresses. It seems that the other propositions treat the lack by adding internal loads caused by the residual stresses to the applied enforced displacements. As the comparison purpose, the results obtained by adding the internal loads to the applied enforced displacements are also shown in the Fig.23 as the corresponding results. The results correspond to the other propositions and are merged into them. The proposed formula is also compared with the experimental results ${ }^{16}$. The experimental result formulated by the mean minus two standard derivation curve shows qualitative and quantitative agreement with the proposed formula, approximately. Since the experimental data are the results tested using the stub columns, the reference plates might be supported in between simply and fixedly. Therefore, it seems that the comparison result with the proposed formula and the experimental data is reasonable.

\section{CONCLUDING REMARKS}

The above conclusions and recommendations are based on the ultimate stability strengths of the cylindrical shell panels under the combined edgeloads and on a limited amount of theoretical work within the structural parameter range of the practical steel arch and/or girder bridge structures. 


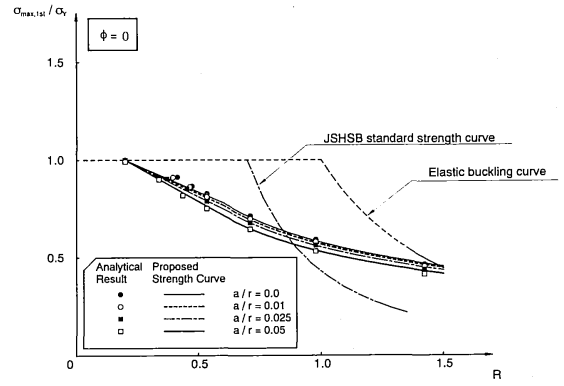

Fig.19 Comparison of Analyzed and Predicted Strengths for Various of $\mathrm{a} / \mathrm{r}$ for $\phi=0$

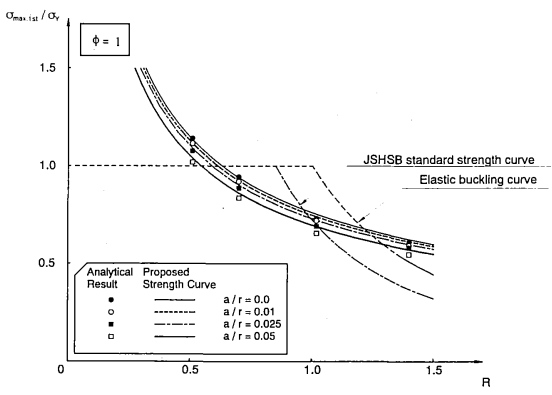

Fig.20 Comparison of Analyzed and Predicted Strengths for Various of $\mathrm{a} / \mathrm{r}$ for $\phi=1$

Research is clearly needed on experimental definings. As the formulas proposed herein are easier to use and no instability analysis needs to be performed on the cylindrical panels, it can be recommended for practical predicting. Finally, the authors are grateful to Messrs. Y. Nagamine and S. Miyagi, graduate students of University of Ryukyu, for drawings and typings of the manuscript.

\section{APPENDIX}

$$
\begin{aligned}
{\left[A_{0}\right] } & =\left[\begin{array}{ccccccccc}
1 & 0 & 0 & 0 & 0 & 0 & 0 & 0 & 0 \\
0 & 0 & 0 & 0 & 1 & 0 & 0 & 0 & 0 \\
0 & 1 & 0 & 1 & 0 & 0 & 0 & 0 & 0 \\
0 & 0 & 0 & 0 & 0 & 1 & 0 & 1 & 0 \\
0 & 0 & 1 & 0 & 0 & 0 & 1 & 0 & 0
\end{array}\right] \\
{\left[A_{\theta}\right] } & =\left[\begin{array}{ccccccc}
\Delta u_{11} \Delta u_{21} \Delta u_{31} & 0 & 0 & 0 & 0 & 0 & 0 \\
0 & 0 & 0 & \Delta u_{12} \Delta u_{22} \Delta u_{32} & 0 & 0 & 0 \\
\Delta u_{12} \Delta u_{22} \Delta u_{32} \Delta u_{11} \Delta u_{21} \Delta u_{31} & 0 & 0 & 0 \\
0 & 0 & 0 & \Delta u_{13} \Delta u_{23} \Delta u_{33} \Delta u_{12} \Delta u_{22} \Delta u_{32} \\
\Delta u_{13} \Delta u_{23} \Delta u_{33} & 0 & 0 & 0 & \Delta u_{11} \Delta u_{21} \Delta u_{31}
\end{array}\right] \\
{\left[B_{k}\right] } & =\left[\begin{array}{cccccc}
B_{1 k} & 0 & 0 \\
0 & B_{1 k} & 0 \\
0 & 0 & B_{1 k} \\
B_{2 k} & 0 & 0 \\
0 & B_{2 k} & 0
\end{array}\right],\left[C_{k}\right]=\left[\begin{array}{ccc}
C_{1 k} & 0 & 0 \\
0 & C_{1 k} & 0 \\
0 & 0 & C_{1 k} \\
C_{2 k} & 0 & 0 \\
0 & C_{2 k} & 0
\end{array}\right]
\end{aligned}
$$

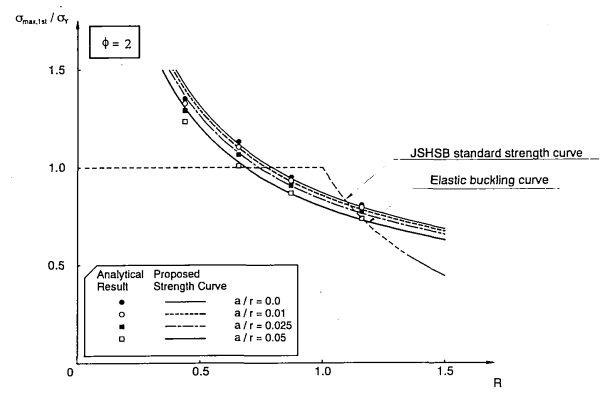

Fig.21 Comparison of Analyzed and Predicted Strengths for Various of $\mathrm{a} / \mathrm{r}$ for $\phi=2$

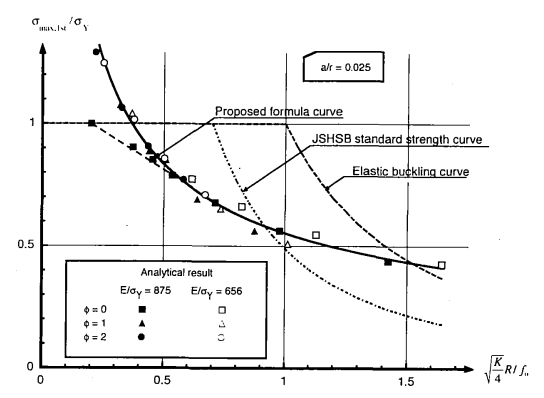

Fig.22 Comparison of Analyzed and Predicted Strengths for Various of $\phi$ and $E / \sigma_{Y}$

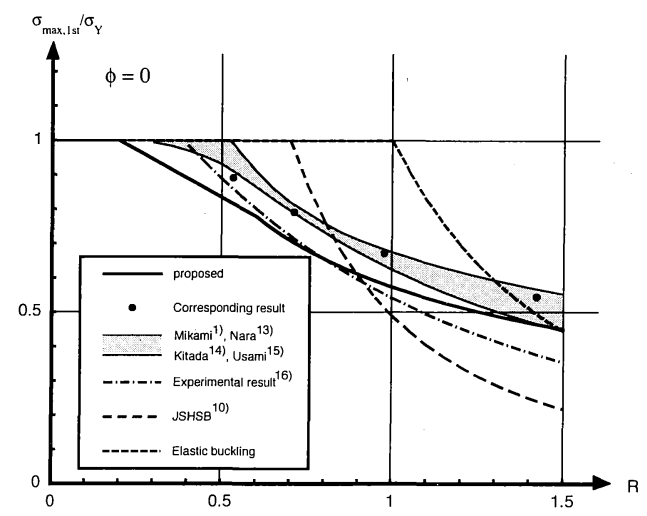

Fig.23 Comparison of Proposed and Other's Strengths

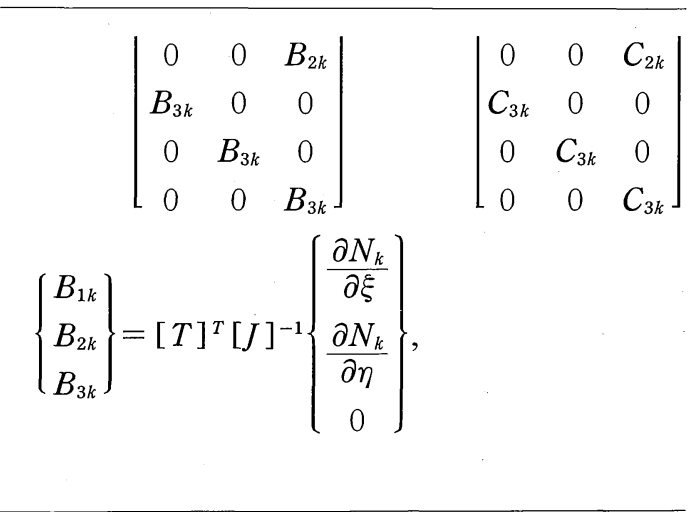




$$
\begin{aligned}
& \left\{\begin{array}{l}
C_{1 k} \\
C_{2 k} \\
C_{3 k}
\end{array}\right\}=[T]^{T}[J]^{-1}\left\{\begin{array}{c}
\zeta \frac{\partial N_{k}}{\partial \xi} \\
\zeta \frac{\partial N_{k}}{\partial \eta} \\
N_{k}
\end{array}\right\} \\
& {\left[H_{k}\right]=\left[\begin{array}{ccc}
B_{1 k} & 0 & 0 \\
0 & B_{2 k} & 0 \\
B_{2 k} & B_{1 k} & 0 \\
0 & B_{3 k} & B_{2 k} \\
B_{3 k} & 0 & B_{1 k}
\end{array}\right],\left[C_{k}\right]=\left[\begin{array}{ccc}
C_{1 k} & 0 & 0 \\
0 & C_{2 k} & 0 \\
C_{2 k} & C_{1 k} & 0 \\
0 & C_{3 k} & C_{2 k} \\
C_{3 k} & 0 & C_{1 k}
\end{array}\right]}
\end{aligned}
$$

\section{REFERENCES}

1) Mikami, I., Matsumoto, H., Tsuji, S. and Tanaka, K. : Compression Strength of Cylindrical Panels with Initial Imperfections, Journal of Structural Engineering, JSCE, Vol.36 A, pp.217 228, 1990 (in Japanese).

2) Nakai, H., Kitada, T., Ohminami, R. and Kawai, T. : A Study on Analysis and Design of Web Plate in Curved Girder Bridges Subjected to Bending, Proc. of JSCE, No.368/I-5, pp.235 244, 1986 (in Japanese).

3) Kuranishi, S. and Hiwatashi, S. : Elastic Behavior of Web Plates of Curved Plate Girders in Bending, Proc. of JSCE, No.315, pp.1 12, 1981 (in Japanese).

4) Fujii, K. and Ohmura, H. : Nonlinear Bending Behavior of Curved Girder-Web with Initial Deflections, Journal of Structural Engineering, JSCE, Vol.35 A, pp.117 126, 1989 (in Japanese).

5) Yabuki, T. and Arizumi, Y. : A Constitutive Modeling for Local Plate-Buckling of Cylindrical Shell Panel, Proc. of Annual Technical Session 1, JSCE, September, 1992 (in Japanese).

6) Yabuki, T., Yashiro, S. and Arizumi, Y. : Lateral Stability Strength of Thin-Walled Steel Box Girders with High Depth, Proc. of Annual Technical Session 1, JSCE,
September, 1992 (in Japanese).

7) Surana, K.S. : Geometrically Nonlinear Formulation for the Curved Shell Elements, International Journal for Numerical Method in Engineering, Vol.19, pp.581 615, 1983.

8) Little, G.H. : Rapid Analysis of Plate Collapse by Live-energy Minimisation, Int. J. Mech. Sci., Vol.19, pp.725 744, 1977.

9) Commettee of Inquiry into the Basis of Design and Method of Erection of Steel Box Girder Bridges, Appendix 1: Interin design and workmanship rules. Part 2: Design rules. HMSO, London, 1973.

10) Japan Road Association : Japanese Specification for Highway Standard Bridges, 1990 (in Japanese)

11) Nishino, F. : Buckilng Strength of Columns and their Component Plates, Fritz Engineering Laboratory Reoprt, No.290. 10, Lehigh University, 1964.

12) Yabuki, T., Le-WuLu and Kuranishi, S. : An Ultimate Strength Design Aid for Fixed-End Steel Arches under Vertical Loads, Proc. of JSCE, Structural Eng./Earthquake Eng., Vol.4, No.1, pp.115-123, April, 1987.

13) Nara, S., Tsuda, M. and Fukumoto, Y. : Evalution of Ultimate Strength of Steel Plates with Initial Imperfections under In-plane Bending and Compression, Proc. of JSCE, No.392/I-9, pp.259 264, 1988 (in Japanese).

14) Komatsu, S. and Kitada, T. : A Study on the Ultimate Strength of Compression Plate with Initial Imperfections, Proc. JSCE, No.270, pp.1 14, 1978 (in Japanese).

15) Usami, T. and Tenkumo, $\mathrm{H}$ : Ultimate Strength and Effective width of Plates in Compression and Bending, Proc. JSCE, No.441/I-19, pp.77 85, 1992 (in Japanese).

16) Fukumoto, Y. and Itoh, Y. : Basic Compressive Strength of Steel Plates from Test Data, Proc. JSCE, Structural Eng./Earthquake Eng., No.344/I-1, pp.91 101, 1984.

(Received March 18, 1993)

種々の圧縮を受ける円筒シェルパネルの終局強度とその実用 評価

矢吹哲哉・有柱康則・八代 茂

本論文は，初期たわみおよび残留応力を有する鋼円筒シェルパネルの直線辺端部に圧 縮と曲げが作用した場合の極限強度についてパラメトリック解析を行い，その特性を検 討したものである. 解析はアイソパラメトリックシェル要素モデルによる弾塑性有限変 位を考慮した有限要素法である。 さらに，それらの結果に基づいて，実用に便ならしめ るための鋼円筒シェルパネル極限強度実用算定式の導出を行った。 